\title{
WHY METAETHICS NEEDS EMPIRICAL MORAL PSYCHOLOGY
}

\author{
JEROEN HOPSTER \\ University of Graz and University of Twente \\ j.k.g.hopster@uni-graz.at \\ MiCHAEL KLENK \\ Delft University of Technology \\ m.b.o.t.klenk@tudelft.nl
}

SUMMARY: What is the significance of empirical moral psychology for metaethics? In this article we take up Michael Ruse's evolutionary debunking argument against moral realism and reassess it in the context of the empirical state of the art. Ruse's argument depends on the phenomenological presumption that people generally experience morality as objective. We demonstrate how recent experimental findings challenge this widely-shared armchair presumption and conclude that Ruse's argument fails. We situate this finding in the recent debate about Carnapian explication and argue that it illustrates the necessary role that empirical moral psychology plays in explication preparation. Moral psychology sets boundaries for reasonable desiderata in metaethics and, therefore, it is necessary for metaethics.

KEY WORDS: experimental moral psychology, evolutionary debunking arguments, fruitfulness, conceptual ethics, Michael Ruse

RESUMEN: ¿Qué papel desempeña la psicología moral y empírica para la metaética? En este artículo analizamos el argumento evolutivo de Michael Ruse contra el realismo moral y lo contrastamos con las últimas investigaciones empíricas. El argumento de Ruse depende de la asunción fenomenológica de que la gente generalmente considera la moralidad como objetiva. Demostramos cómo las recientes investigaciones experimentales desafían esta asunción ampliamente compartida y no contrastada experimentalmente, por lo que concluimos que el argumento de Ruse falla. Nuestras conclusiones se sitúan en el reciente debate sobre la explicación de Carnap y muestran el papel necesario que la psicología moral y empírica tienen en la preparación de explicaciones. La psicología moral establece los límites de los desiderata metaéticos razonables, y, por tanto, es necesaria para la metaética.

PALABRAS CLAVE: psicología moral experimental, argumentos evolutivos, fertilidad, ética conceptual, Michael Ruse

\section{Introduction}

In some fields of philosophy, empirical encroachment has long been eyed with the utmost suspicion. This certainly rings true for the field of metaethics, which for the better part of the twentieth century was 
detached from empirical work. G.E. Moore, whose Principia Ethica (1903 [2004]) is regarded by many metaethicists as the field's foundational treatise, coined the infamous 'naturalistic fallacy' in the same book. ${ }^{l}$ Moore's influential work did little to foster interaction with empirical disciplines, especially with an evolutionary bent. Michael Ruse typified the prevailing twentieth century attitude towards 'evolutionary ethics" as follows: "[I]t has been enough for the student to murmur the magical phrase 'naturalistic fallacy' and then he or she can move on to the next question, confident of having gained full marks thus far on the exam" (1995b).

Empirical scientists, in turn, long did not pay much attention to metaethics. The treatment of those who did was often cursory and dismissive, as exemplified by E.O. Wilson's suggestion "that the time has come for ethics to be removed temporarily from the hands of philosophers and biologicised" (1975). Wilson was serious about his purpose but did not seriously engage with the leading metaethical works of his time (Kitcher 2006). Empirical science and metaethics remained two worlds apart.

Well underway in the twenty-first century this situation has certainly changed. Empirical research about the origins and psychological mechanisms of moral behaviour has mushroomed, generating several fertile research programs, such as research into morality's evolutionary origins (e.g. Tomasello 2016), morality's psychological foundations and neurological underpinnings (e.g. Graham et al. 2013; Greene 2016), and its sociological and anthropological nature. ${ }^{2}$ Several (meta-)ethicists, in turn, have turned to the sciences to corroborate or undermine metaethical claims (Street 2006; Joyce 2006; Appiah 2009; Prinz 2007; Doris and Plakias 2008). Additionally, several experimental studies have been conducted with the aim of scrutinising non-specialists' opinions about metaethical issues, such as the semantics of moral disagreement (Khoo and Knobe 2016), or that of objectivity versus relativity of moral issues (Sarkissian et al. 2011; Sarkissian 2016). Whether the resulting findings about 'folk metaethics' have implications for traditional metaethical questions is an issue of ongoing dispute. ${ }^{3}$ But even among those who deny that such findings have metaethical relevance, opposition has taken on a

${ }^{1}$ The point Moore sought to make in coining the 'naturalistic fallacy' is that 'goodness' is a simple property, which cannot be analysed in terms of other properties - a point that differs from how many commentators have used the concept.

${ }^{2}$ Cf. Klenk 2019b.

${ }^{3}$ Cf. Hopster 2019b. 
different flavour from dismissals of the past. The empirical work is scrutinised with seriousness, and critics often engage with the empirical details as much as supporters do. At the same time, many of the leading empirical researchers have become more sensitive to the philosophical finesses of metaethical questions. Philosophers are no longer called upon to hand over their work, and murmuring the magical phrase 'naturalistic fallacy' no longer provides anyone with an easy pass. The extreme positions of completely rejecting the relevance of empirically informed moral psychology for philosophy, or completely relinquishing moral philosophy for an empirical approach, now appear implausible.

However, despite their greater interaction, the precise relation between metaethics and empirically informed moral psychology is still subject to intense debate, ${ }^{4}$ and coming to terms with this relation requires subtlety. In what follows, we intend neither to overstate the relevance of empirical work for metaethics nor to dismiss it altogether. The field of metaethics may be too diverse to allow for interesting claims that specify its general relation to empirical psychology. Instead, in this paper, we proceed by looking at a specific case-study in which empirical psychology and metaethics interact. Subsequently, we flesh out what general lessons this case-study can teach us about the relevance of empirical psychology for metaethics.

The case-study we will look at is Michael Ruse's debunking argument against what he originally called moral objectivism (1995a, $2009,1998)$ - a view that, in contemporary metaethics, is commonly referred to as moral realism. Moral realism —understood to encompass both naturalist and non-naturalist variants - is the view that there are stance-independent moral truths about which we can have at least some knowledge (Enoch 2011; Shafer-Landau 2003; e.g. Brink 1989). Ruse's argument is well-known, and its general aim of explaining away moral realism through an argument supported by scientific findings about morality is widely shared in the current debate about evolutionary debunking arguments (e.g. Braddock 2016). But while its philosophical presuppositions have been fiercely discussed (e.g. Clarke-Doane 2016), only little attention has been paid to a crucial empirical presupposition of Ruse's argument: that people experience morality as having an objective, external foundation. The underexplored empirical presupposition and new empirical insights that shed light on it make Ruse's argument ideal as a case-study for our purposes.

${ }^{4}$ Cf. Klenk 2019a. 
We will first demonstrate how novel empirical moral psychological findings about folk perceptions of moral objectivity are required for a full assessment of Ruse's argument, and ultimately force us to reject one of its fundamental propositions. We then locate and defend the importance of empirical moral psychology for metaethics in more abstract terms, by scrutinising the role it plays in Carnapian explication preparation (which we define below). We argue that empirical moral psychology is required to sharpen our empirical grasp of the moral phenomena that constitute the input of metaethical analysis. This is significant since these phenomena constitute the basic building blocks of metaethical theorising: if they are ill-understood, metaethicists might be led astray. We conclude that metaethics needs empirical psychology: empirical findings can play a key role in refining the desiderata of metaethical analysis.

\section{Ruse's Argument against Moral Realism}

Michael Ruse's debunking argument targets the metaethical view that morality is 'objective' in the sense of having foundations that are external to human beings (e.g. Ruse 1995a). Ruse's supposition that morality has these features relies on a phenomenological assumption about the nature of human moral experience, and a scientific hypothesis about the origins of this phenomenology. First, Ruse assumes that our moral experience is underwritten by a strong claim to objectivity: "An important part of the phenomenological experience of substantive ethics is not just that we feel that we ought to do the right and proper thing, but that we feel that we ought to do the right and proper thing because it truly is the right and proper thing" (2009).

In other words, we typically perceive moral demands as having a strong authority which does not depend on our inclinations or even on those of any other human agent: an external authority. This apparent external authority, and the strong feeling of obligation to which moral demands give rise, are components of what we might call morality's supposed objectivity.

Second, Ruse hypothesises that this supposed objectivity is an illusion that our genes have instilled in us to make us good social cooperators. Thinking of moral demands as being externally imposed serves a motivational function. As has been documented by research in social psychology, ${ }^{5}$ when we perceive a demand as objective, we

\footnotetext{
${ }^{5}$ Cf. Nichols 2004.
} 
are typically more inclined to comply with it. Complying with moral demands, in turn, is typically evolutionarily advantageous because of the cooperation benefits it serves. Hence, the supposed objectivity of moral demands may be a proximate mechanism to foster fitnessenhancing social interactions.

Ruse advances these empirical claims to substantiate a metaethical conclusion: the postulate that morality is 'objective' in the sense of having foundations external to us is explanatorily redundant, and should be discarded. Or to use Ruse's terminology: "morality is a collective illusion foisted upon us by our genes" (1998).

To emphasise, Ruse does not mean to deny that we have moral beliefs and act in characteristically moral ways; rather, the illusion he refers to is that morality is objective: "What is really important to the evolutionist's case is the claim that ethics is illusory inasmuch as it persuades us that it has an objective reference" (1998, emphasis added).

According to Ruse, thinking that morality is objective is an integral part of the biological function of morality: "morality simply does not work (from a biological perspective) unless we believe that it is objective" (1998, p. 253). However, he claims that "in light of what we know of evolutionary processes, the objective foundation [of morality] has to be judged redundant" (1995a, p. 241). Ruse argues:

[The objectivist must agree] that his/her ultimate principles are (given Darwinism) redundant. You would believe what you do about right and wrong, irrespective of whether or not a "true" right and wrong existed! The Darwinian claims that his/her theory gives an entire analysis of our moral sentiments. Nothing more is needed. Given two worlds, identical except that one has an objective morality and the other does not, the humans therein would think and act in exactly the same ways. (1998)

This shows, Ruse argues, that "morality has no objective reference" and that "morality is subjective" instead (1995a). Ruse's argument thus puts pressure on objective types of moral realism, of both naturalistic and non-naturalistic bent, in favour of a form of moral subjectivism. ${ }^{6,7}$

${ }^{6}$ Cf. Prinz 2007.

${ }^{7}$ Naturalist moral realism may be able to withstand Ruse's argument (cf. Joyce 2006), mainly because the moral facts posited by naturalist moral realism need not be explanatorily idle (and thus not subject to Ockham's Razor). Nonetheless, as Joyce argues, it is an open question whether naturalist types of realism can indeed explain the apparent objectivity of moral facts in suitable fashion. 
Ruse's argument relies on the philosophical presupposition that entities (like moral facts) earn their 'ontological keep' by figuring in the best explanation of an empirical phenomenon. ${ }^{8}$ The metaethical debate about the legitimacy of this principle goes back to Harman (1977), and is now still subject to intense discussion within the debate on evolutionary debunking arguments. ${ }^{9}$

But the debate thus far has failed to engage with another crucial set of presuppositions of Ruse's argument: its empirical presuppositions. For present purposes we will thus set aside the potential epistemological and meta-philosophical problems with Ruse's argument and turn to its empirical presuppositions.

\section{Revisiting Ruse's Argument Using Moral Psychology}

In this section, we provide a concrete example for the claim that metaethics needs empirical moral psychology to fully and reliably assess metaethical arguments. To do so, let us focus on the empirical grounds of Ruse's argument. There are two claims underlying Ruse's argument against moral realism:

- Phenomenological presumption: people commonly experience morality as objective in the sense of having an external foundation that does not depend on the attitudes or perspectives of themselves or other human beings.

- Scientific claim: this trait - morality's supposed objectivity as expressed by the phenomenological presumption - is an evolutionary adaptation.

Both of these claims rest on empirical assumptions: an assumption about the nature of folk phenomenology, and an assumption about

\footnotetext{
${ }^{8}$ More precisely, most commentators interpret Ruse's argument as an argument that relies on a methodological appeal to parsimony (the methodological principle is known as Ockham's Razor). Roughly, Ockham's Razor suggests that we should prefer the simplest solution, which often means that we should prefer explanations with fewer explananda. In order to make use of Ockham's Razor, Ruse's argument must also invoke a metaphysical principle that licenses existence claims (e.g. 'objective moral facts' exist) depending on whether they play a role in a parsimonious explanation. Ruse's argument suggests that objective moral facts do not play a role in a parsimonious explanation, hence one would not be justified in positing their existence. This argument is indeed controversial, partly because there are concerns with appealing to Ockham's Razor in moral philosophy. See Klenk (2018b) for discussion, and criticism, of the philosophical presuppositions of Ruse's argument.

${ }^{9}$ Cf. Clarke-Doane 2016; Klenk 2018b.
} 
the evolutionary function of this phenomenology. However, Ruse provides little detailed argument in support of these claims. Perhaps this should not come as a surprise. When Ruse first presented his argument in the 1980s, no experimental research had been done on the nature of folk moral phenomenology, and evolutionary work on the origins of morality, while indeed existent, was rather coarsegrained.

However, in recent years, a substantial amount of empirical and theoretical work has focused on these issues. For instance, experimental psychologists have begun to empirically scrutinise whether lay respondents indeed regard moral demands as strongly objective. ${ }^{10}$ Furthermore, evolutionary psychologists have recently come up with reasonably specific hypotheses about the evolutionary function of moral objectivism, suggesting that ascribing objectivity to moral judgements may be functional in more intricate ways than Ruse himself proposed (DeScioli and Kurzban 2013; Stanford 2018). Since these hypotheses lend some support to Ruse's more generic claim that morality is an evolutionary adaptation, a reassessment of Ruse's phenomenological and scientific hypotheses is called for.

Naturally, such reassessment will not salvage the potential epistemological and meta-philosophical flaw in Ruse's argument. If his appeal to explanatory parsimony is untenable in a metaethical context, then no further empirical work can rescue his original argument to the effect that morality is subjective. But we will argue that if the target of Ruse's argument is cast in somewhat more subtle terms, it can lead to an interesting and tenable metaethical conclusion nonetheless. Moreover, to work towards this conclusion by reassessing the empirical assumptions underlying Ruse's original argument serves to illustrate in more detail how empirical moral psychology can be relevant for contemporary metaethics.

\subsection{Ruse's Argument and the Phenomenological Presumption}

Ruse's phenomenological presumption that people commonly experience morality as objective, in the sense of having an external foundation, is commonplace and shared by moral philosophers across the metaethical spectrum (Enoch 2011; e.g. Blackburn 1984; Brink 1989; Mackie 1977). ${ }^{11}$ Moral philosophers, and metaethicists in particular,

${ }^{10}$ Cf. Goodwin and Darley 2008, 2012, 2010; Sarkissian et al. 2011; Wright et al. 2013; Beebe 2014; Fisher et al. 2017.

${ }^{11}$ See Pölzler (2018) for a helpful discussion of the presumptive claim in recent in moral philosophy, and its metaethical relevance. 
have long regarded it as a desideratum to vindicate morality's objectivity on theoretical grounds. But why so? Like Ruse, they support this desideratum with findings from moral phenomenology, paired with observations about the nature of moral discourse and moral behaviour. Phenomenologically, it seems that the demands of morality are objective in a way that matters of taste or etiquette are not. ${ }^{12}$ For instance, contrary to many conventional norms, moral norms are often strongly enforced; transgression typically leads to punishment. What is more, even in the absence of external enforcement, moral demands are sometimes experienced as being externally imposed; hence, their force has been claimed to be "authority-independent" (Brink 1989). Additionally, archetypical moral norms purport to be impartial: they apply categorically to all members of a given group, irrespective of existing loyalties and relations (DeScioli and Kurzban 2013). These considerations suggest that there is more to moral objectivity than mere intersubjective consensus, and have led many metaethicists to endorse a view similar to Ruse's phenomenological claim. Whether the phenomenological presumption can ultimately be justified -i.e. whether it serves as a valid characterisation of morality - has been subject to perennial discussion among metaethicists (Gert and Gert 2017). But even if some metaethicists question whether the phenomenological presumption is a valid claim about the nature of morality, they rarely question its validity as a claim about the subjective experience of morality - not only that of a few select philosophers but as a claim about the moral experience of most if not all people.

Therefore, it is important to emphasise that Ruse's phenomenological claim should be interpreted as implying a claim about the folk concept of morality, rather than a theoretical concept. Though metaethical theories often trade in theoretical concepts, the beginning of an inquiry often legitimately employs a folk concept ${ }^{13}$ Understood as a characterisation of a folk concept, Ruse's presupposition can be regarded almost as an axiom of moral philosophy. It represents an almost universally accepted starting point for further theorising about morality.

Given its almost axiomatic status, it should not surprise us that the phenomenological presumption escaped scrutiny in Ruse's argument. However, as we show in the next section, empirical moral psychology has begun to change this situation in important ways.

${ }^{12}$ Cf. Enoch 2015.

${ }^{13}$ Cf. McPherson and Plunkett 2017, 2020. 


\subsection{Revising Ruse's Argument: evidence from Empirical Moral Psychology}

Over the last decade or two, the question of whether people regard morality as objective has been taken up as a subject of empirical scrutiny. ${ }^{14}$ This has proved to be a fertile area of empirical moral psychological research, in which an increasing number of studies are being undertaken, effectively installing a new subfield of moral psychology: the psychology of metaethics. The findings of this body of research suggest that people's commitment to moral objectivity is much less clear-cut than Ruse and many other moral philosophers assume.

A standard approach of this line of research is to conduct surveys, whereby respondents are presented with a series of moral statements (e.g. 'killing is wrong'). Subsequently, respondents are asked to judge whether these statements are true or false, and whether persons who make a different judgement can be mistaken - hence, whether or not there can be faultless disagreement on this issue (e.g. Goodwin and Darley 2008, 2010, 2012; Wright et al. 2013; see self-referring citation for discussion). These two judgements are then translated into an 'objectivity score'. Presumably, if respondents think both that a moral statement has a truth-value, and that there cannot be faultless disagreement about its truth or falsity, then they experience the statement as being objective, in the sense of having an external foundation that does not depend on the attitudes or perspectives of themselves or other human beings. Hence, these studies might be regarded as a test-case for Ruse's phenomenological claim.

A key insight that has emerged from these studies, however, is that there is in fact considerable inter- and intra-subject variance regarding the supposed objectivity of moral judgments. That is, not all people judge a moral proposition like 'killing is wrong' to be objectively true or false, and some people who judge that 'killing is wrong' is objectively true or false do not think the same about other moral propositions, like "consensual sex with siblings is morally wrong'.

As these findings indicate, Ruse's phenomenological claim is only partly corroborated by empirical research. Empirical moral psychology presents us with a much more refined picture of people's phenomenology, suggesting substantial variance in the degree to which people experience moral statements as objective. There is also an important degree of flexibility, in that people seem to experience

${ }^{14}$ Cf. Goodwin and Darley 2008, 2010, 2012; Sarkissian et al. 2011; Wright et al. 2013; Beebe 2014; Fisher et al. 2017. 
some moral issues as more objective than others, or portray particular moral judgements as objective in some contexts but not in others.

In light of this more refined picture, we should conclude that the phenomenological presumption has been too coarse-grained. People experience some aspects of morality as objective, but not all, and aspects that appear objective to some people do not appear to be objective to others. While the phenomenological presumption may aptly characterise some particular moral experiences, it cannot pass as a generalisation about moral experience as such.

Rejecting the phenomenological presumption has important ramifications for Ruse's argument. Naturally, since his conclusion rests on the phenomenological presumption, and the presumption does not hold, the conclusion does not obtain. For our purposes, however, the important point is not primarily the failure of Ruse's argument, but what this shows about the significance of empirical moral psychology. Ruse's argument was built on faint moral psychological insight that lacked empirical rigour. With the empirical apparatus brought to bear on the question about people's experience of morality, the picture has become more nuanced and more complicated, but truer to form. Moreover, while the complications show that Ruse's original argument was not sound, they simultaneously provide an impetus for further metaethical reflection about morality's true form.

\subsection{The Psychological Determinants of Metaethical Judgements: a Pilot Study}

The insight that there is substantial inter-subject variance in metaethical judgements has led some researchers to explore the psychological or social determinants of people's metaethical views in greater detail. What makes people regard or present a moral issue as objective? Some moral psychologists have found evidence that social consensus is an important factor in determining people's objectivist commitments. For instance, Goodwin and Darley (2012) presented undergraduates with false information about the percentage of students from the same institution who agreed with them about the correctness of certain moral statements. Undergraduates presented with low consensus estimates were significantly less likely to regard statements as objective than respondents presented with high consensus estimates. Similarly, Beebe (2014) found that having respondents reflect upon the extent of societal disagreement about moral statements decreased their attributions of objectivity regarding those statements. 
These findings may lead to the impression that conformity bias plays an important role in ascriptions of moral objectivity: in judging a moral issue to be objective, people simply follow the majority vote. Neither of these studies, however, suggests that social consensus is the only determinant of regarding moral issues as objective or even the principal determinant. One further determinant might be what degree of importance agents attribute to moral issues: if subjects regard a moral issue as being of great personal importance, this may positively influence their rating of the statement's objectivity. That such a self-serving mechanism might be at work in making metaethical judgements gains some initial plausibility from studies of first-order normative judgements, where a similar self-serving mechanism often seems to be at work. Various studies indicate that people often strategically advocate moral rules that serve their own interests and benefit themselves more than others. ${ }^{15}$ For example, it has been found that people generally approve of having driverless cars designed in such a way that they minimise overall harm (e.g. by preventing the car from hitting pedestrians), but that when it comes to buying their own car, the same people will opt for cars designed to save the passengers at all costs (Bonnefon et al. 2016).

Note that assessing the determinants of people's metaethical ascriptions is not merely of psychological and sociological interest, but may also be of metaethical interest, to the extent that metaethicists are invested in specific claims about the functions of morality. This brings us back to Ruse, who claimed that objectifying moral demands is functional in biological terms. The hypotheses highlighted here do not directly speak to this claim, but the fact that people's tendency to objectify moral issues has specific psychosocial determinants does raise interest in the psychosocial and evolutionary functions that objectification might serve. We will return to this in section 4 .

The hypothesis that personal importance is a determinant of moral objectivity judgements has not yet received experimental scrutiny. Nevertheless, it is an interesting hypothesis to explore, especially in the context of tying assumptions about the objectivity of moral phenomenology to evolutionary considerations. After all, if it turns out that objectifying moral demands is strategic for individuals, then this may tie in with the evolutionary hypothesis about the adaptiveness of objectifying moral demands.

We performed a pilot study, to test whether the level of objectivity subjects ascribe to moral issues indeed correlates with the personal

${ }^{15}$ See DeScioli and Kurzban 2013 and DeScioli 2016 for references. 
importance they ascribe to the respective issues. We did so by collecting a total of $n=21$ test subjects via Amazon Turk (n after removing participants through attention-checks and removing incomplete records) and presenting them with 35 statements, mostly concerning moral issues, such as 'discriminating against someone on the basis of race is unacceptable'. Question categories (factual, moral, taste, religious) were assigned by us, but the classification was informed by the study of Wright et al. 2013, in which subjects self-identified moral issues (the statements we used were mostly taken from this study). ${ }^{16}$ Subjects then rated each statement according to how important they found the truth or falsity of the statement. They indicated whether the statement was true, false or just an opinion or attitude, and whether another person who disagreed with them about the truth or falsity of the judgment had to be wrong or whether both could be right. Following Goodwin and Darley 2008, 'objectivity scores' were computed as a categorical variable with 1 point for considering a statement to be true or false and 1 point for judging that one party must be wrong in a disagreement about the statement (hence, $2=$ max. objectivity score, $1=$ medium objectivity score, $0=$ subjectivist).

Pairwise t-tests found a significant positive relation between the degree to which a subject judges a moral issue to be objective and how important the subject judges the truth or falsity of the proposition to be, with a considerable effect for medium scores $(t=2.6822$, $\mathrm{df}=21, \mathrm{p}$-value $=0.01395)$ and a strong effect for high objectivity scores $(t=7.4187, \mathrm{df}=21, \mathrm{p}$-value $=2.7 \mathrm{e}-07)$. Hence, our findings provide preliminary support for the hypothesis that subjects who regard the truth of a statement as being of personal importance are prone to consider the truth or falsity of judgments concerning that statement as more objective. This, in turn, provides support for our hypothesis that perceptions of objectivity are driven by subjectively experienced importance and that the variance in perceived objectivity observed in other studies is explained by the fact that different people experience different issues as important.

Naturally, these findings are by no means conclusive. For instance, they point to a correlation between objectivity and ascribed importance, but the pilot study allows no inference about causation: as far as experiment goes, regarding an issue as objective might be a consequence of regarding the issue as important, or, alternatively,

\footnotetext{
${ }^{16}$ That is, the subjects in Wright et al.'s study classified statements as moral or not moral themselves.
} 
respondents might regard an issue as important because they think its truth or falsity is an objective matter. Further research needs to be done in order to settle this matter.

But while not intending to make a claim about robust findings, we do think that this pilot study suggests — with a greater level of confidence than a mere armchair intuition - that personal importance indeed modulates the objectivity people attribute to moral judgments. The correlation is worthy of further exploration, which might proceed, amongst others, by experimental means.

In the context of empirically assessing Ruse's argument, our findings allow for a more informed rejection of the phenomenological presumption. Existing research on folk perceptions of morality has already suggested that the armchair phenomenological presumption is too simplistic. What was missing is a comprehensive explanation of the variance in perceptions of objectivity. Our pilot study adds another piece of the puzzle: the armchair phenomenological presumption fails because perceptions of objectivity are partly driven by the importance ascribed to the respective issue, and people have different attitudes towards what is important.

\section{Empirical Moral Psychology as Concept Explication}

Our assessment of Ruse's metaethical argument in light of recent advances in empirical moral psychology illustrates the power of one concrete use of empirical moral psychology in metaethics: empirical moral psychology is required to assess the soundness of arguments built on empirical premises. Though Ruse's argument can and should also be assessed based on its philosophical merits (e.g. is an appeal to explanatory parsimony legitimate in an argument against moral realism?), we have demonstrated how empirical sophistication opens up a new angle of assessment that otherwise remains out of reach. Given that Ruse's argument, like so many other influential arguments in recent metaethics, is partly built on empirical premises, we need a sound empirical apparatus to fully and reliably assess these arguments. ${ }^{17}$ Therefore, empirical moral psychology is necessary for contemporary metaethics. ${ }^{18}$

${ }^{17}$ As an anonymous reviewer pointed out, this claim is not specific to metaethics. We agree; an argument along similar lines might also be applicable to other philosophical subfields. However, metaethics does constitute something of a special case in relation to empirical moral psychology, as their subject matters are closely related.

${ }^{18}$ Compare the arguments of Street 2006; Joyce 2006; Greene 2016 that rely heavily on empirical premises. Similarly, the burgeoning debate on moral disagreement 
Of course, our claim thus far is contingent on the fact that there are (influential) arguments in metaethics that rely on empirical premises. Critics might object that such arguments have no proper place in metaethics or philosophy in general, which ought to be occupied only with the a priori, ${ }^{19}$ or that their empirical premises are superfluous for reaching the respective argument's conclusion. ${ }^{20}$ We reject the metaphilosophical view behind the first objection (as our main interlocutor in this article, Ruse, would too), though an assessment is beyond the scope of this paper. The second objection, though more credible than the first, can be answered because it relies on an overly narrow construal of the metaethical debate. Metaethical debate surely relies on arguments in the strict logical sense (i.e. premises that entail a conclusion), and in these arguments, empirical premises may not always be required. But metaethics is also an exercise in theory building, and in determining what our theories ought to explain, and in explaining the phenomena that need explaining, empirical input does play an important and indeed necessary role.

To illustrate, let us return to the preceding assessment of Ruse's argument, which already suggests what the systematic role of empirical moral psychology is in metaethics. Ruse's argument is partly an attempt at theory building. On that view, we can see Ruse as proposing first a concept of morality in line with the phenomenological presumption that needs to be explained and then to offer a theory to 'best' explain that phenomenon. That is, he suggests that the phenomenon of morality as experienced as objective needs explaining and that a naturalistic, subjectivist theory does the explaining best.

From that perspective, Ruse is engaging in what others have called "explication preparation" (Shepherd and Justus 2015) at the beginning of a process of Carnapian concept explication (Carnap 1950). Experimental philosophy has been defended as an integral part of explication preparation (Shepherd and Justus 2015), and we shall argue in what follows that empirical moral philosophy, in general, has its natural, and necessary, role in explication preparation in metaethics. In doing so, we will show how paying close attention to Ruse's exemplary argument can answer some objections that have been levelled

relies increasingly on empirical premises about the true extent of moral disagreement, cf. Doris and Plakias 2008. For an overview and a recent connection to the debunking debate, see Bergmann and Kain 2014; Klenk 2018a.

${ }^{19}$ Cf. Casullo and Thurow 2013.

${ }^{20}$ For an example of the latter, compare Klenk 2017 on the evolutionary debunking argument of Street 2006. 
against viewing experimental philosophy as an exercise in explication preparation.

Explication, as introduced by Carnap (1950), is a method for replacing terms and concepts with more precise counterparts, in order to facilitate theorising. The imprecise term or concept with which we start, called the explicandum, may "belong to everyday language or to a previous stage in the development of scientific language" (Carnap 1950). ${ }^{21}$ The method aims to replace the explicandum with a more precise and fruitful explicatum. The method begins with an informal clarification of the explicandum, which Shepherd and Justus (2015) have called "explication preparation". During that stage, the aim is to arrive at a clear understanding of the concept in question (Carnap 1950).

We can now see how moral psychology is required for concept explication. In the context of Ruse's concern with the folk concept of morality, explication preparation would involve getting an accurate grasp of the folk concept of morality, and moral psychology is required for this step. Arguably, the empirical findings we discussed above suggest that the folk concept of morality is such that, roughly, some but not all moral issues are objective, which represents a refinement of Ruse's phenomenological presupposition. In that way, experimental philosophy is required for and has a natural role to play in concept explication, as several philosophers have recently suggested (Shepherd and Justus 2015; Lindauer 2019). In continuation with those arguments, we argue for a broadened scope. Empirical moral psychology, in general, is a tool required for explication preparation in metaethics.

However, the account of the relation between empirical moral psychology and metaethics in terms of explication preparation faces a significant objection. As explained, explication preparation is a step in the process of explication, which has as its goal the formulation of a fruitful, possibly refined concept (vis-à-vis the folk-concept one started with). But empirical moral psychology as we have discussed it does not help with formulating such a concept per se -it only shows that concepts (or, rather, words associated with them) are used and interpreted differently by different speakers (Pinder 2017). Taken on their own, the findings about the perceived objectivity of morality only suggest that there is more variety, but that does not

\footnotetext{
${ }^{21}$ Indeed, as suggested in section 3.1., Ruse's phenomenological presupposition says something about the folk concept of morality, which then ought to be explicated.
} 
settle how the concept ultimately ought to be used. So, the objection goes, empirical moral psychology in itself does not contribute to explication preparation, contrary to our claim.

In order to illustrate the objection more concretely, let us go back to the phenomenological presumption. In the process of concept explication, the objection goes, the phenomenological presumption provides us with a view about the correct or adequate moral experience, or moral experience true to form, if you will. And that just is to experience a moral issue as objective and grounded in an external reality, or so the proponents of the phenomenological presumption might argue. Whoever is engaged in the explication could, therefore, look for various considerations for and against a particular interpretation of the concept and the experimental findings themselves play no decisive role. They merely tell us that there are alternatives to a conceptualisation of morality as objective, but they do not tell us which of the alternative options we should choose. Moreover, because the empirical findings suggest that some people experience morality in line with the phenomenological presumption at least about some moral issues, the empirical evidence reviewed does not settle how the concept 'morality' ought to be explicated. The point is that, despite the novel experimental findings, the crucial philosophical task, and the crucial task for concept explication, remains to choose which concept to adopt. And for that task, the objection goes, empirical moral psychology plays no role. ${ }^{22}$

We stress, however, that the objection does not affect our minimal claim that empirical moral psychology is required to evaluate the soundness of metaethical arguments, like Ruse's, that rely on empirical premises. In that sense, we can maintain that moral psychology is required for metaethics even if our claim about the role of moral psychology in concept explication fails.

Moreover, we need not backtrack at all, because the objection can be answered. Empirical moral psychology itself provides part of the background against which we can check whether a particular rendering of a concept is apt for explication. That is, it allows us to evaluate whether a particular choice of explicandum is a good one to start with. The criteria for evaluating whether we have found an apt explicandum are minimally given by our theoretical aims. Insofar as we aim to analyse a folk concept (like Ruse and many other metaethicists do), we must find ways to correctly grasp the folk concept. Moral psychology is required for this aim, as we demonstrated above. Our

${ }^{22}$ Cf. Pinder 2017. 
argument and case study based on Ruse's argument thus confirms the idea of Shepherd and Justus (2015), who defend experimental methods as a way to sharpen an explicandum when they write that they help by "pinpoint[ing] the content that merits attempted preservation [in the explicatum] and the content that should be abandoned" (Shepherd and Justus 2015).

We briefly illustrate the role of empirical methods for explication. Consider what our experimental data tell us about the concept of morality. When we start with concept explication, we want to get a good grasp of the (folk) concept that we try to explicate. From the armchair, we may have adopted a concept in line with Ruse's phenomenological presumption. But our data tell us that there is significant variance in people's perception of the objectivity of moral issues. Thus, a more accurate view of the folk concept of morality would be that people take some moral issues to be objective but not all, and moral psychology helped us to get there. ${ }^{23}$ To put it differently, it is useful to distinguish between questions of specification and questions of application. We (heavily) rely on philosophy to specify and refine the aims of our inquiry (e.g., the aim could be to analyse the folk concept MORALITY) and we (heavily) rely on moral psychology in applying these criteria to choosing an explicandum (e.g. we would reject that the folk concept MORALITY suggests that all moral issues are objective).

Moreover, our earlier assessment of the phenomenological presumption demonstrates that Shepherd and Justus's evaluation of the significance of moral psychology for concept explication is apt but incomplete Empirical moral psychology also plays a role in partly setting the criteria by which we evaluate the fruitfulness of an explicatum. According to Lindauer (2019), a moral concept's fruitfulness depends on how well it serves the aim of moral inquiry. Lindauer proposes, in line with some remarks by Aristotle, and much recent 'functionalist' interpretations of morality, that the aim of moral inquiry is to help us solve practical problems. Consequently, we can evaluate a moral concept's fruitfulness in terms of its helpfulness in solving our practical problems (Lindauer 2019). Though we are largely sympathetic to Lindauer's interpretation of the aims of moral inquiry, our argument need not depend on it. Instead of interpreting the criteria for fruitfulness in terms of practical aims, they can also be spelled out in terms of theoretical aims. Arguably, metaethics

\footnotetext{
${ }^{23}$ Of course, our cautionary remarks about the need to further corroborate these experimental findings still apply.
} 
is an attempt to analyse how actual moral thought and talk (and behaviour, more generally) fits into reality (McPherson and Plunkett 2017). A fruitful concept, on that view, is one that allows us to explain how the content of the concept 'fits into reality' so that it, for example, coheres with our existing picture of reality and that it enables inference and prediction. As moral psychology contributes to our understanding of reality, so it contributes to our criteria for evaluating how the contents of concepts 'fit' into reality. For example, when our picture of reality includes a view of morality as an adaptation (which we discuss in more detail below), then a criterion for fruitfulness will partly be a matter of whether or not a given concept coheres with that picture of reality. Insofar as moral psychology thus contributes to the picture of reality, it plays an important role in setting the criteria for fruitfulness.

Therefore, moral psychology is required not only for questions of application (to wit, questions about what concepts would serve our aims, as discussed above), but indirectly also for questions of specification (to wit, questions about what the aims of inquiry should be).

We will again return to Ruse's argument to illustrate our point and to show how empirical moral psychology partly determines fruitfulness. Ruse's argument contains a scientific presumption about the evolutionary function of morality. In what follows (4.1.-4.3.), we argue that recent empirical findings indeed corroborate this presumption. Crucially, the empirically corroborated view of morality as evolutionary adaptation provides an evaluative context in which the explication of 'morality' as objective in the sense of the phenomenological presumption becomes unlikely to be fruitful. That is, it does not help us meet the purpose of moral inquiry. ${ }^{24}$ This hitherto underacknowledged impact on explication preparation is a key role for empirical moral psychology in metaethics.

\subsection{The Functions of Objectifying Moral Demands}

Recall that Ruse's scientific claim is that morality's supposed objectivity is functional in evolutionary terms: it benefits the reproductive success of agents who possess this trait. Why so? According to Ruse: "[T]here are good (biological) reasons why it is part of our nature to objectify morality. If we did not regard it as binding, we would ignore it. It is precisely because we think that morality is more than mere subjective desires, that we are led to obey it" (1995a).

${ }^{24}$ Cf. Lindauer 2019. 
A somewhat similar view has been expounded by John Mackie (1977), who also argued that objectifying moral judgments was functional - although he emphasised its psychosocial rather than its biological function. According to Mackie, it often serves interpersonal relations well to behave as morality requires: "We need morality to regulate interpersonal relations, to control some of the ways in which people behave towards one another, often in opposition to contrary inclinations. We, therefore, want our moral judgments to be authoritative" (1977). For instance, think of situations which involve a tragedy of the commons: to coordinate action by referring to common moral values might help to solve social predicaments. In contemporary metaethics, the idea that morality serves an evolutionary function is widely accepted. Barkhausen writes: "A major function of moral language and the cognitive capacities required for its use is to coordinate on mutually beneficial rules of conduct in situations with scope for common gain" (2016).

There is much recent philosophical support for the function thesis (Sterelny and Fraser 2016; Kitcher 2011), and several philosophers invoke it in metaethical arguments (Sauer 2019; Joyce 2006). Especially over the last decade, these suppositions about morality's evolutionary and psychosocial functions have become a topic of closer scrutiny by experimental and evolutionary psychologists. Their work, we will illustrate in this section, gives rise to a more fine-grained view than Ruse originally proposed. But the general tenor of this work adds to the plausibility of Ruse's guiding insight: our objectivist moral phenomenology can be explained in evolutionary terms.

\subsection{Coordination}

Mackie argued that one function of moral demands is to foster social coordination. But why should moral values be regarded as objective to serve this function? Followers of Mackie, such as Joyce (2006), have argued that objectifying moral demands has a motivational upshot: feeling an internal sense of moral obligation motivates us to behave as morality requires. Perhaps this is part of the explanation, but as Stanford (2018) has recently argued, it cannot be the full story. We are also motivated by subjective experiences, such as the experience of pain or hunger, which we do not cast in terms of having an external authority. What additional function is served by supposing moral demands to be objective?

Wright et al. $(2013 ; 2014)$ have formulated a hypothesis about the psychosocial function of moral objectivism that may answer this 
question. Building on experimental findings which suggest that subjects' attitudes towards regarding moral issues as objective is quite flexible and diverse, they suggest that a capacity to modulate the objectivity ascribed to moral issues helps to coordinate dialogue and action both within and between sociocultural groups:

\begin{abstract}
Viewing a moral issue as objectively grounded removes it from the realm of legitimate personal/social negotiation [...]. Viewing a moral issue as non-objectively grounded, on the other hand, allows people to acknowledge its moral significance $[\ldots]$, while at the same time maintaining room for choice, dialogue, and debate. (Wright et al. 2014)
\end{abstract}

We think that Wright et al.'s hypothesis is along the right lines: presenting a moral demand as objective typically signals an unwillingness of the agent making the demand to easily change her mind about it. But we think there might be more to the story. Apart from its psychosocial function, objectifying moral demands might also serve an evolutionary function.

\title{
4.3. Signalling
}

An influential hypothesis about morality's evolutionary function has been formulated by DeScioli and Kurzban (2013), who have argued in detail in support of the thesis that the main evolutionary function of moral judgment is choosing sides in a conflict. Choosing sides is a strategic interaction problem that involves a perpetrator, a victim and a third-party condemner. Different solutions are possible, some which involve decision procedures that would never be advisable in making individual choices, but may be beneficial in multiplayer interactions.

One possible solution is to choose sides on the basis of pre-existing alliances. However, this strategy has the downside of escalating conflicts, resulting in greater costs. A second solution is to choose sides on the basis of power: third parties side with the most powerful party in the conflict. However, this strategy has the downside of concentrating power in the hands of high-status individuals and may lead to authoritarianism and exploitation. A third solution is to choose sides by focusing on the contents of an action. Some actions may be flagged as never-to-be-done or categorically wrong; this public signal can subsequently coordinate third-party judgment. This solution is characteristic of moral conflicts, in which bystanders typically coordinate which side they choose not on the basis of the identities of 
the disputants but on the basis of their actions. Indeed, some characteristic features of morality - its impartiality, non-consequentialist characteristics and the categorical nature of moral demands - can be explained by this strategic interaction framework.

Assuming the view of DeScioli and Kurzban (2013) is along the right lines, might we be able to extend it to the metaethical domain? We submit that a plausible hypothesis, building on the empirical findings highlighted in section 3 , is that objectifying moral issues is instrumental to the function of choosing sides. ${ }^{25}$ For parties engaged in conflict, presenting an issue as objective serves as an effective instrument to force third parties to choose sides in the debate. By objectifying an issue, members of the party engaged in conflict signal their intention to stand their ground, and force bystanders to choose: on this issue, they are either with them or against them. Hence, objectifying moral issues may serve a signalling function: it signals that agents care about an issue and are not easily prepared to change their minds about it. As a result, presenting moral issues as objective may be an effective means to form moral alliances, to enhance ingroup cohesion and to demarcate the out-group.

\subsection{Revisiting Concept Explication Using Empirical Moral \\ Psychology}

The objectivity agents ascribe to moral issues can be modulated. We have already provided some preliminary support for the hypothesis that one of the determinants of objectivist judgments is the personal importance that agents ascribe to moral issues through our pilot study (see 3.2.). This hypothesis fits well with recent work in evolutionary moral psychology, which lends support to the idea that ascribing objectivity to moral judgments serves an evolutionary signalling function: to objectify a moral issue serves as a public signal that agents are willing to stand their ground with regard to this issue since the issue is of personal importance to them.

If DeScioli and Kurzban's hypothesis, and our extension of it, are along the right lines, then this provides a plausible evolutionary background for understanding the origins of the 'objectivist phenomenology' typical of moral judgments and provides clear support for the view that perceiving morality as objective serves an evolutionary function.

Crucially, this moral psychological insight now reflects back on the issue of explication preparation that we started with in this section.

${ }^{25}$ Cf. Stanford 2018, who advances a related hypothesis. 
Recall that the objection against using moral psychology for concept explication was that, ultimately, the empirical research plays no role in actually selecting a concept for explication. We can now see that this objection is short-sighted. Empirical moral psychology itself provides us with an evaluative context that plays a significant role for determining a concept's fruitfulness.

More specifically, consider what would play a part in determining the fruitfulness of an explication of the concept MORALITY. Given the availability of a plausible evolutionary explanation of morality, as outlined above, a fit with that explanation will partly determine fruitfulness. That is, a view of reality that includes morality as an evolutionary adaptation (as outlined above) will partly determine that a fruitful concept is one that can be aligned with that view. In that sense, moral psychology is required for evaluations of fruitfulness.

Naturally, empirical moral psychology does not generate criteria for fruitfulness out of thin air. It is only with the given aim of analysing how concepts fit with empirical reality that moral psychology necessarily contributes to establishing the criteria for judging fruitfulness. Of course, moral realists may want to insist on the phenomenological presumption that moral demands are typically regarded as objective. Realists present a metaethical explanation for this: we think of moral demands as objective because we have some intuitive grasp of a stance-independent moral reality. ${ }^{26}$ But the advances in empirical moral psychology we have presented demonstrate that this is not the only kind of explanation that could be advanced. Indeed, in this article we have argued that a convincing explanation for the more complex and flexible objectivism found in experimental research comes from evolutionary psychology: that some (but not all) moral issues are associated with a strong sense of objectivity has to do with the psychosocial benefits of objectifying them, specifically those moral issues that are of personal importance to agents. ${ }^{27}$

\footnotetext{
${ }^{26}$ See Hopster 2019a for criticism.

${ }^{27}$ Interestingly, in our pilot-study we did not find any 'core' fundamental moral issues in the sense that they were judged to be objective by all study participants. Empirically, we could search for 'objectivity clusters' (i.e. topics judged to be objective by groups of people). An anonymous referee suggested this might be a potential objection on the realists' behalf: if there are some moral issues that are considered as important and objective by all, then these could be constructed in a moral realist sense. We disagree, however. Philosophically, even the finding that all people would judge some moral issues to be objective would not get objectivists off the hook: our theory would predict that issues that are important to all people are
} 
Naturally, empirical moral psychology does not determine concept choice -it does not provide an algorithm if you will. However, given the good fit our alternative explanation has with findings from experimental metaethics, and given its evolutionary plausibility, there is pressure to regard an interpretation of morality along the lines of the realist's phenomenological presumption as un-fruitful.

\section{Conclusion}

What is the metaethical significance of empirically informed moral psychology? We have positioned ourselves between the extreme poles of rejecting moral psychology or taking it to dominate moral philosophy and argued that empirically informed moral psychology is a required means to explicate the moral phenomena we investigate in moral philosophy. We demonstrated the beneficial influence of moral psychology through a discussion of the phenomenological presumption, the view that people generally experience morality as in some sense objective, and in particular by focusing on an unduly neglected argument by Michael Ruse, which strongly depends on the phenomenological presumption. We then reviewed recent work on folk perceptions of moral objectivity, which suggests that there is wide inter- and intra-subjective variance in perceived objectivity judgments. Importantly for our purposes, this experimental work shows that the phenomenological presumption, as originally understood, is mistaken. Thus, empirically informed moral psychology can have metaethical significance by providing us with a better view on the moral phenomena in question, and consequently with refining the desiderata of successful metaethical theorising.

This conclusion indicates that empirical findings do not merely speak to the external validity of metaethical claims. Additionally, the dynamics between metaethics and empirical findings can stimulate new insights and breed new hypotheses, both in empirical moral psychology and in metaethics. Metaethical claims about the 'objective seemings' of our moral phenomenology have inspired various studies in experimental moral psychology, effectively generating a new subfield of moral psychology: the psychology of metaethics. This empirical work, in turn, can be used as a stepping stone for further metaethical theorising, as well as metaphilosophical theorising about the desiderata of metaethical analysis. Hence, the interaction between

also judged to be objective by all people. Moral realists would have to disentangle that relation and show, for example, that some moral issues are judged to be objective by all people despite not being deemed personally important by all. 
metaethics and empirical psychology stimulates theorising on both sides, even on issues where they remain in tension: this very tension can create fertile ground to advance metaethical scholarship. ${ }^{28}$

\section{REFERENCES}

Appiah, A., 2009, Experiments in Ethics, Harvard University Press, Cambridge, Mass.

Barkhausen, M., 2016, "Reductionist Moral Realism and the Contingency of Moral Evolution", Ethics, vol. 126, no. 3, pp. 662-689. (doi: $10.1086 / 684708)$.

Beebe, J.R., 2014, "How Different Kinds of Disagreement Impact Folk Metaethical Judgments", in Hagop Sarkissian and Jennifer Cole Wright (eds.), Advances in Experimental Moral Psychology, Bloomsbury Academic, London, pp. 167-187.

Bergmann, M. and P. Kain, 2014, Challenges to Moral and Religious Belief. Disagreement and Evolution, Oxford University Press, Oxford.

Blackburn, S., 1984, Spreading the Word. Groundings in the Philosophy of Language, Oxford University Press, Oxford.

Bonnefon, J.-F., A. Shariff and I. Rahwan, 2016, "The Social Dilemma of Autonomous Vehicles", Science, vol. 352, no. 6293, pp. 1573-1576. (doi: 10.1126/science.aaf2654).

Braddock, M., 2016, "Debunking Arguments and the Cognitive Science of Religion", Theology and Science, vol. 14, no. 3, pp. 268-287. (doi: 10.1080/14746700.2016.1191878).

Brink, D.O., 1989, Moral Realism and the Foundations of Ethics, Cambridge University Press, Cambridge.

Carnap, R., 1950, Logical Foundations of Probability, Chicago University Press, Chicago, Ill.

Casullo, A. and J.C. Thurow, 2013, The A Priori in Philosophy, Oxford University Press, Oxford.

Clarke-Doane, J., 2016, "Debunking and Dispensability", in Uri D. Lei-

\footnotetext{
${ }^{28}$ Many thanks to Jonathan Phillips for help with our pilot study and to the audience at the Evolutionary Ethics conference at Oxford Brookes for helpful discussion. We thank Laura García Portela and Giuseppe Guagliardo for help with the Spanish translation. Our joint work on this paper has been supported by the Dutch Organisation for Scientific Research (project no 360-20-340). Additionally, Jeroen received support from an NWO Rubicon Fellowship, and Michael from a Niels Stensen Fellowship; parts of his work have also been part of the project ValueChange that has received funding from the European Research Council (ERC) under the European Union's Horizon 2020 research and innovation programme under grant agreement No 788321 .
} 
bowitz and Neil Sinclair (eds.), Explanation in Ethics and Mathematics, Oxford University Press, Oxford, pp. 23-36.

DeScioli, P., 2016, "The Side-Taking Hypothesis for Moral Judgment", Current Opinion in Psychology, vol. 7, pp. 23-27. (doi: 10.1016/j.copsyc. 2015.07.002).

DeScioli, P. and R. Kurzban, 2013, "A Solution to the Mysteries of Morality", Psychological bulletin, vol. 139, no. 2, pp. 477-496. (doi: 10.1037/a0029065).

Doris, J.M. and A. Plakias, 2008, "How to Argue about Disagreement: Evaluative Diversity and Moral Realism", in Walter Sinnott-Armstrong (ed.), Moral Psychology: The Cognitive Science of Morality: Intuition and Diversity, MIT Press, Cambridge, Mass., pp. 303-331.

Enoch, D., 2015, "Why I Am an Objectivist about Ethics (And Why You Are, Too)", in Russ Shafer-Landau (ed.), The Ethical Life: Fundamental Readings in Ethics and Moral Problems, Oxford University Press, Oxford.

- 2011, Taking Morality Seriously. A Defense of Robust Realism, Oxford University Press, Oxford.

Fisher, M., J. Knobe, B. Strickland and F.C. Keil, 2017, "The Influence of Social Interaction on Intuitions of Objectivity and Subjectivity", Cognitive Science, vol. 41, no. 4, pp. 1119-1134. (doi: 10.1111/cogs.12380).

Gert, B. and J. Gert, 2017, "The Definition of Morality", in Edward N. Zalta (ed.), Stanford Encyclopedia of Philosophy, Fall.

Goodwin, G.P. and J.M. Darley, 2012, "Why Are Some Moral Beliefs Perceived to be More Objective Than Others?", Journal of Experimental Social Psychology, vol. 48, no. 1, pp. 250-256. (doi: 10.1016/j.jesp.2011.08.006).

—_, 2010, "The Perceived Objectivity of Ethical Beliefs", Review of Philosophy and Psychology, vol. 1, no. 2, pp. 161-188. (doi: 10.1007/s13164-009-0013-4).

- 2008, "The Psychology of Meta-ethics: Exploring Objectivism", Cognition, vol. 106, no. 3, pp. 1339-1366. (doi: 10.1016/j.cognition.2007. 06.007).

Graham, J., J. Haidt, S. Koleva, M. Motyl, R. Iyer, S.P. Wojcik and P.H. Ditto, 2013, "Moral Foundations Theory", Advances in Experimental Social Psychology, vol. 47, pp. 55-130.

Greene, J.D., 2016, "Beyond Point-and-Shoot Morality", in S. Matthew Liao (ed.), Moral Brains, Oxford University Press, Oxford, pp. 119-149.

Harman, G., 1977, The Nature of Morality. An Introduction to Ethics, Oxford University Press, New York.

Hopster, J., 2019a, "Explaining Historical Moral Convergence", Philosophical Studies, pp. 1-19. (doi: 10.1007/s11098-019-01251-x).

—, $2019 b$, "The Metaethical Implications of Experiments about Folk Moral Objectivism", Philosophical Psychology, vol. 32, pp. 831-852. (doi: 10.1080/09515089.2019.1627304). 
Joyce, R., 2006, The Evolution of Morality, MIT Press, Cambridge, Mass. Khoo, J. and J. Knobe, 2016, "Moral Disagreement and Moral Semantics", Noûs, vol. 38, no. 3, pp. 109-143. (doi: 10.1111/nous.12151).

Kitcher, P., 2011, The Ethical Project, Harvard University Press, Cambridge, Mass.

— 2006, "Ethics and Evolution: How to Get Here from There", in Stephen Macedo and Josiah Ober (eds.), Primates and Philosophers, Princeton University Press, Princeton, New Jersey.

Klenk, M., 2019a, "Evolutionary Ethics", Introduction to Philosophy: Ethics, ed. George W. Matthews, Rebus Community.

— 2019 b, "Moral Philosophy and the 'Ethical Turn' in Anthropology", Zeitschrift für Ethik und Moralphilosophie, vol. 2, no. 2, pp. 331-353. (doi: 10.1007/s42048-019-00040-9).

_ 2018a, "Evolution and Moral Disagreement", Journal of Ethics and Social Philosophy, vol. 14, no. 2, pp. 112-142. (doi: 10.26556/jesp.v14i2. 476).

— 2018b, "Survival of Defeat: Evolution, Moral Objectivity, and Undercutting", PhD thesis, Utrecht University, Utrecht.

— , 2017, "Old Wine in New Bottles", Ethical Theory and Moral Practice, vol. 20, no. 4, pp. 781-795. (doi: 10.1007/s10677-017-9797-y).

Lindauer, M., 2019, "Experimental Philosophy and the Fruitfulness of Normative Concepts", Philosophical Studies, vol. 2, no. 1, p. 31. (doi: 10.1007/s11098-019-01302-3).

Mackie, J.L., 1977, Ethics. Inventing Right and Wrong, Penguin Books, London.

McPherson, T. and D. Plunkett, 2020, "Conceptual Ethics and the Methodology of Normative Inquiry", Conceptual Engineering and Conceptual Ethics, in Tristram McPherson and David Plunkett (eds.), Oxford University Press, Oxford, pp. 274-303.

— 2017, "The Nature and Explanatory Ambitions of Metaethics", in Tristram Colin McPherson and David Plunkett (eds.), The Routledge Handbook of Metaethics, Routledge, New York, pp. 1-25.

Moore, G.E., 1903 [2004], Principia Ethica, Dover Publications, Mineola, New York.

Nichols, S., 2004, Sentimental Rules. On the Natural Foundations of Moral Judgment, Oxford University Press, Oxford, New York.

Pinder, M., 2017, "Does Experimental Philosophy Have a Role to Play in Carnapian Explication?", Ratio, vol. 30, no. 4, pp. 443-461. (doi: 10.1111 /rati.12164).

Pölzler, T., 2018, Moral Reality and the Empirical Sciences, Routledge, New York.

Prinz, J.J., 2007, The Emotional Construction of Morals, Oxford University Press, Oxford. 
Ruse, M., 2009, "The Biological Sciences can Act as a Ground for Ethics", in Francisco J. Ayala and Robert Arp (eds.), Contemporary Debates in Philosophy of Biology, Wiley-Blackwell, Oxford, United Kingdom, pp. 297-315.

—_, 1998, Taking Darwin Seriously. A Naturalistic Approach to Philosophy, Prometheus Books, Amherst, New York.

- , 1995a, "Evolutionary Ethics: A Phoenix Arisen", in R. Paul Thompson (ed.), Issues in Evolutionary Ethics, SUNY series in Philosophy and Biology, State University of New York Press, Albany, New York, pp. 225-248.

-, 1995b, Evolutionary Naturalism. Selected Essays, Routledge, London.

Sarkissian, H., 2016, "Aspects of Folk Morality: Objectivism and Relativism", in Justin M. Sytsma and Wesley Buckwalter (eds.), A Companion to Experimental Philosophy, Wiley-Blackwell, Hoboken, New Jersey, vol. 61, pp. 212-224.

Sarkissian, H., J. Park, D. Tien, J.C. Wright and J. Knobe, 2011, "Folk Moral Relativism", Mind \& Language, vol. 26, no. 4, pp. 482-505. (doi: 10.1111/j.1468-0017.2011.01428.x).

Sauer, H., 2019, "The Argument from Agreement", Ratio, vol. 32, no. 4, pp. 339-352. (doi: 10.1111/rati.12233).

Shafer-Landau, R., 2003, Moral Realism. A Defence, Oxford University Press, Clarendon, Oxford, New York.

Shepherd, J. and J. Justus, 2015, "X-Phi and Carnapian Explication", Erkenntnis: An International Journal of Analytic Philosophy, vol. 80, no. 2, pp. 381-402.

Stanford, P.K., 2018, “The Difference between Ice Cream and Nazis: Moral Externalization and the Evolution of Human Cooperation", Behavioral and Brain Sciences, vol. 41, p. 28. (doi: 10.1017/S0140525X17001911).

Sterelny, K. and B. Fraser, 2016, "Evolution and Moral Realism", The British Journal for the Philosophy of Science, vol. 14, axv060. (doi: 10.1093/bjps/axv060).

Street, S., 2006, "A Darwinian Dilemma for Realist Theories of Value", Philosophical Studies, vol. 127, no. 1, pp. 109-166.

Tomasello, M., 2016, A Natural History of Human Morality, Harvard University Press, Cambridge, Mass.

Wilson, E.O., 1975, Sociobiology. The New Synthesis, Belknap Press of Harvard University Press, Cambridge, Mass.

Wright, J.C., P.T. Grandjean and C.B. McWhite, 2013, "The Meta-Ethical Grounding of Our Moral Beliefs", Philosophical Psychology, vol. 26, no. 3, pp. 336-361. (doi: 10.1080/09515089.2011.633751).

Wright, J.C., C.B. McWhite and P.T. Grandjean, 2014, "The Cognitive Mechanisms of Intolerance: Do our Metaethical Commitments Matter?", 
in Joshua Knobe, Tania Lombrozo and Shaun Nichols (eds.), Oxford Studies in Experimental Philosophy, Oxford Studies in Experimental Philosophy, Oxford Bibliographical Society, Oxford, vol. 1., pp. 28-61.

Received: April 24, 2020; revised: July 3, 2020; accepted: August 11, 2020. 